\title{
ALLOMETRIC SCALING OF WINGATE ANAEROBIC TESTSCORES IN YOUNG SOCCER PLAYERS
}

\author{
Borislava Petrova \\ National Sports Academy "Vassil Levski"
}

\begin{abstract}
In this study, we:(a) developed allometric exponents for scaling Wingate anaerobic test (WAnT) power data that are effective in controlling body mass(BM) influence; and (b) established a normative WAnT data set for young soccer players. Forty-six players completed a standard WAnT. Allometric exponents and percentile ranking for peak power (PP), average power $(A P)$ and power output for $30 \mathrm{~s}$ (W 30 s) were established. Allometric exponents " $b$ " for PP, AP and $W(30$ s) scaled for BM were 0.72,0.78 and 0.85 respectively using braking force $75 \mathrm{~g}{ }^{\mathrm{kg}-1}$, markedly higher from the theoretical suggested of $b=0.67$. The study shows the possibilities of applying the allometric scaling in the coaches practice. If these exponents in allometric scaling of young soccer players are used, WAnT power values will provide coaches with valid means for comparing power production between individuals without the confounding influence of $B M$.
\end{abstract}

Key words: Wingate anaerobic test, allometric scaling

\section{INTRODUCTION}

Soccer is a very popular sport performed by men and women, children and adults with different levels of qualification. Soccer is an intermittent activity sport, taxing both the aerobic and anaerobic systems. During competitions, the players' workload intensity ranges from walking to sprinting. Thus, to sufficiently sustain the ability of performing during a soccer match, a player must possess an above average aerobic component to assist rapid recovery between intermittent bouts of high intensity. Soccer requires a strong anaerobic component too that combines strength, speed and power. (Vanderford et al, 2004). Work-rate analysis has been used to investigate the physiological demands of soccer by a large number of authors (Reilly, Thomas,1976; Rienzi et al, 2000; Bangsbo et al, 1991; Krustrup, 2005). The data provided by the investigators are of interest to practitioners. Such data could have an impact upon the training regimen, fitness assessment and selection of players (Carling et al, 2005).

During a 90-minute game, elite-level players run about $10 \mathrm{~km}$ at an average intensity close to the anaerobic threshold. Within this endurance context, numerous explosive bursts of activity are required, including jumping, turning, sprinting, tackling and sustaining forceful contractions to maintain balance and control of the ball against defensive pressure (Stølenetal, 2005). Therefore, the study of the players' anaerobic capacity is important for assessing their functional capacity.

The most commonly used laboratory test for assessing the anaerobic capacity is the 30-second Wingate Anaerobic Test (WAnT). The well-known parameters recorded during the WAnT routine procedure like Peak Power (PP) and Average Power (AP) are traditionally reported in absolute terms- watts (W) or divided by body mass $\left(\mathrm{W} \cdot \mathrm{kg}^{-1}\right)$. These "per ratio scaling" method is used to facilitate the com- 
parison of the measurements recorded from different body mass individuals. It is assumed that thereby scaled performance variables are independent of the subject's body mass. The ratio scaling, however, is the subject of criticism by a number of authors (Nevill et al, 1991; Dooman and Vanderburgh, 2000; Folland et al, 2008; Stickley et al, 2013). "When comparing participants using unscaled data (absolute values), larger participants typically achieve a higher score, with a positive correlation between the variable and BM. When using ratio scaling, the scaled variable is generally overcorrected, thus the smaller participants have an advantage, resulting in a negative correlation between the scaled variable and BM (Oba et al, 2014). For comparative purposes, normalisation of strength measures to body size using allometric scaling is recommended (Folland et al. 2008; Blair et al, 2009; Stefanova, 2002; Stefanova, 2002a,b). The allometric scaling has been shown to be an important tool to control the effect of body mass when interpreting WAnT results. Hetzleret al (2011) developed allometric exponents for scaling WAnT power data for college women. Nedeljkovic et al (2009) and Stickley et al (2013) worked out exponents for WAnT power scores in adult men. We have not found any studies presenting allometric developed exponents for scaling WAnT power data of actively sporting youths.

The aim of the study was to derive allometric exponents for WAnT power scores that are effective in minimizing the body mass influence and to establish normative data for young soccer players. On this basis various options for applying allometric exponents for WAnT power scores in the sports practice could be found. It can be used by the coaches in the analysis of the test results to control the individual performance of the athletes.

\section{Participants}

Forty-six soccer players with $14.45 \pm 0.87$ years of age; height $163.98 \pm 9.49 \mathrm{~cm}$; body mass $51.82 \pm 8.67 \mathrm{~kg}$; BMI 18.75 \pm 1.94 ; maximal heart rate 193,7 \pm 7,2 bpm; maximal oxygen uptake $57.23 \pm 7.53 \mathrm{ml} . \mathrm{kg}^{-1}$ ) who were familiar with exhaustive exercises, volunteered to participate in this study. The subjects were fully informed with the details and discomfort associated with the experiments before they and their parents gave informed consent to volunteer.

\section{Exercise testing procedures}

All study procedures were done in the high-performance physiology laboratory at the Center for Scientific and Applied Research in Sport, National Sports Academy "Vassil Levski”, Sofia.

Anthropometric measurements preceded the testing procedures.

All youth athletes performed the WAnT on a mechanically braked cycle ergometer (Monark, 894 E, Stockholm, Sweden) as described by Inbar et al. (1996).

The test started with a standardized warming up of 5 min cycling at $60 \mathrm{~W}$ and 60 revolution. min $^{-1}$ including two sprints, each lasting $3 \mathrm{~s}$, performed at the end of the 3rd and the 5 th min. The seat height and handle were individually adjusted for the subject's comfort, with the legs being nearly fully extended during each pedal revolution. After 5 min rest the subjects were instructed to pedal as fast as possible for $30 \mathrm{sec}$. A resistance corresponding to $7.5 \%$ of the body mass was applied after an acceleration phase lasting $5 \mathrm{~s}$. Verbal feedback to the time remaining was provided at 15,10 and $5 \mathrm{~s}$ of remaining time while verbal encouragement was given. The subjects continued pedaling after completion of the test with no load for several minutes to cool down.

The WanT twice was completed by four- 
teen participants - at the beginning of the preparatory period of training (Test I) and at the beginning of the competitive period (Test II) after a five months period of specialized training.

Power output was registered each second and expressed in watts $(\mathrm{W})$ and watts per kilogram of body mass (W.kg-1). We analyzed the peak power (PP), average power (AP) and the total power output during the 30 seconds of the supramaximal effort.

\section{Statistics}

Statistical analysis was performed using Excel. Data were expressed as mean $\pm \mathrm{SD}$; Pearson correlations were generated. Log-linear regression was used to determine the allometric exponents.

\section{Allometric Scaling}

We applied the allometric scaling procedure described by Vanderburgh et al (1995). The equation $\mathrm{y}=\mathrm{a} \cdot \mathrm{x}^{\mathrm{b}}$, where $\mathrm{y}=$ outcome variable (power), $x=$ body mass $(\mathrm{kg})$ in which " $\mathrm{a}$ " is the constant multiplier and " $\mathrm{b}$ " is a constant exponent, transformed into a log-linear model so that linear regression could be used to solve the value of " $b$ " (the allometric exponent) for each studied variable. In this study, the equation for power and $\mathrm{BM}$ would be: power $=\mathrm{a} \cdot \mathrm{BM}^{\mathrm{b}}$. The slope of the regression line was used as the allometric scaling exponent (b). Dividing power by $\mathrm{BM}^{\mathrm{b}}$ yields the allometric power index equal to the constant "a", or $\mathrm{a}=$ power. $\mathrm{BM}^{-\mathrm{b}}$. In the case that the scaling exponent is correctly calculated, the correlation between the BM and power trends to zero, i.e. the two variables no longer show any interdependence.

\section{RESULTS}

To provide useful exponents for allometric scaling of the power scores we determined previously that the measured data are normality distributed - the average data and median were very close (for PP - 803.11 and 802.75; for AP - 589.16 and 590.21; and for W 30s -17147.37 and 17151.05). Allometric scaling resulted in the following exponents " $b$ " for BM: 0.72,0.78 and 0.83 for PP, AP and W 30s.

The correlation coefficient between BM and the unscaled, as well as the ratio scaled and allometrically scaled power data are presented in Table 1.

Table 1. Correlation coefficient between body mass and unscaled, ratio scaled and allometrically scaled WAnT power scores of 46 adolescent soccer players

\begin{tabular}{llll}
\hline Score & Peak Power & Average Power & (Work output W 30 s) \\
\hline Unscaled & $\mathrm{r}=0.593 \mathrm{~W}$ & $\mathrm{r}=0.726 \mathrm{~W}$ & $\mathrm{r}=0.741 \mathrm{~W}$ \\
\hline Ratio scaled & $\mathrm{r}=-0.300 \mathrm{~W} \cdot \mathrm{kg}^{-1}$ & $\mathrm{r}=-0.284 \mathrm{~W} \cdot \mathrm{kg}^{-1}$ & $\mathrm{r}=-0.267 \mathrm{~W} \cdot \mathrm{kg}^{-1}$ \\
\hline Allometrically scaled & $\mathrm{r}=-0.032 \mathrm{~W} \cdot \mathrm{kg}^{-0.72}$ & $\mathrm{r}=-0.030 \mathrm{~W} \cdot \mathrm{kg}^{-0.78}$ & $\mathrm{r}=-0.026 \mathrm{~W} \cdot \mathrm{kg}^{-0.83}$ \\
\hline
\end{tabular}

The high correlations found when unscaled data are used, are greatly reduced when ratio scaled is applied. All derived exponents resulted in nonsignificant correlations with BM. It means that the derived allometric ex- ponent successfully remove the influence of BM. Figure 1 presents the relationships between BM and the various methods of scaling the Wingate PP. 

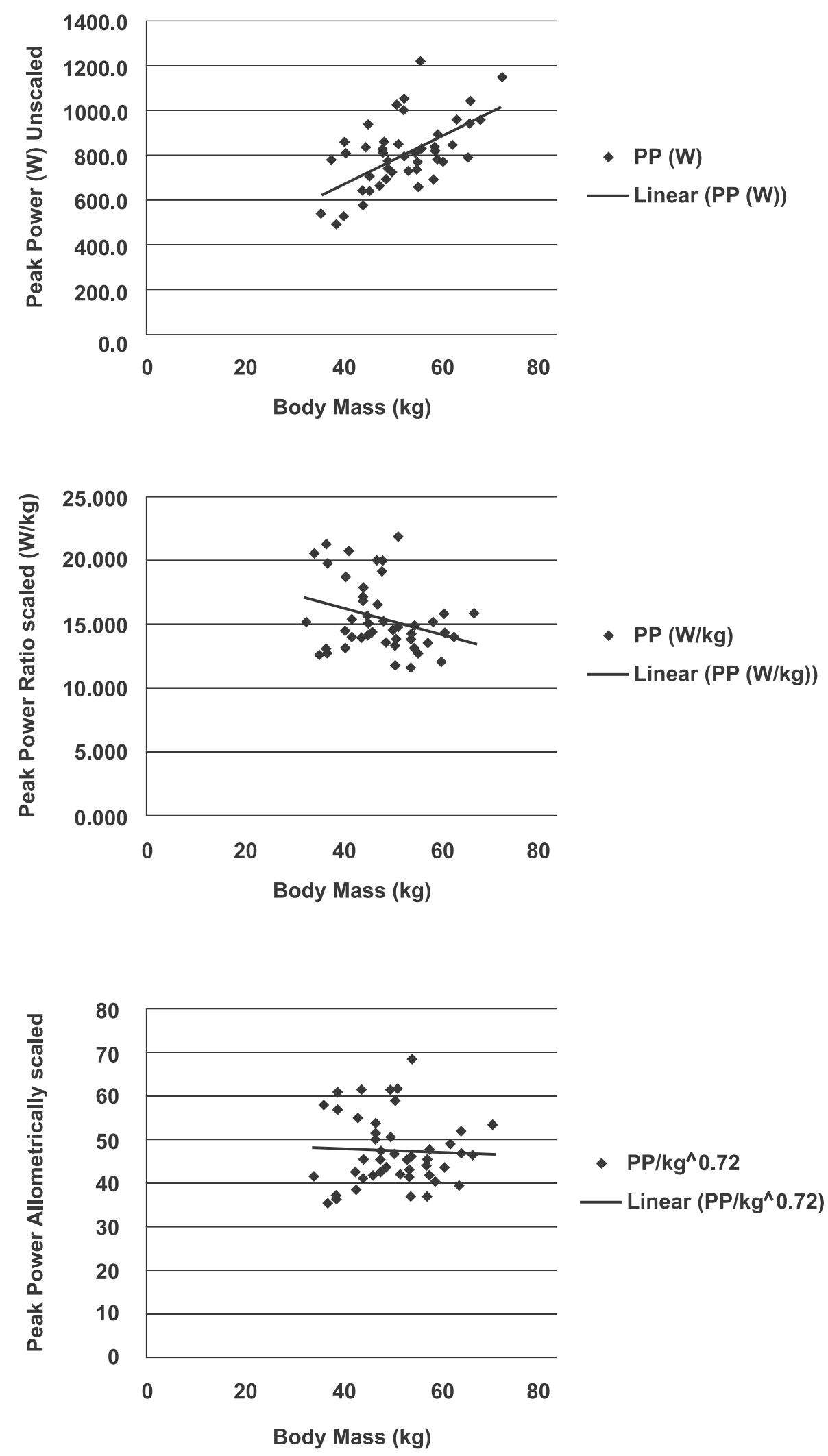

Figure 1. Relationship between BM and Peak Power presented unscaled, ratio scaled and allometrically scaled. The efficacy of each method is demonstrated. 
By applying the percentile technique, we have developed a five-point normative rating scale (Table 2).

Table 2. Percentile norms for unscaled, rate scaled and allometrically scaled Wingate Peak Power, Average power and Total power output (W 30 s) for 14-15-year-old soccer players $(n=46)$

\begin{tabular}{ccccccc}
\hline Parameter & Assessment & Low & Medium & Good & Very good & Excellent \\
\hline \multirow{2}{*}{ PP (W) } & Unscaled & $<611$ & $611-737$ & $737-845$ & $845-936$ & $>936$ \\
\cline { 2 - 7 } & Rate scaled & $<12.8$ & $12.8-13.9$ & $13.9-15.9$ & $15.9-20.1$ & $>20.1$ \\
\cline { 2 - 7 } & $\begin{array}{c}\text { Allometrically } \\
\text { scaled }\end{array}$ & $<38.2$ & $38.2-42.6$ & $42.6-50.6$ & $50.6-59.7$ & $>59.7$ \\
\hline \multirow{2}{*}{ AP (W) } & Unscaled & $<447$ & $447-556$ & $556-626$ & $626-721$ & $>721$ \\
\cline { 2 - 7 } & Rate scaled & $<9.7$ & $9.7-10.6$ & $10.6-11.7$ & $11.7-14.4$ & $>14.4$ \\
\cline { 2 - 7 } & $\begin{array}{c}\text { Allometrically } \\
\text { scaled }\end{array}$ & $<22.3$ & $22.3-25.3$ & $25.3-28.7$ & $28.7-33.3$ & $>33.3$ \\
\hline \multirow{2}{*}{ W 30 s } & Rnscaled & $<13064$ & $13064-16260$ & $16260-18276$ & $18276-20738$ & $>20738$ \\
\cline { 2 - 7 } & Rate scaled & $<278.5$ & $278.5-312.2$ & $312.2-345.9$ & $345.9-411.5$ & $>411.5$ \\
\cline { 2 - 7 } & $\begin{array}{c}\text { Allometrically } \\
\text { scaled }\end{array}$ & $<4168.0$ & $4168.0-5063.8$ & $5063.8-5750.3$ & $5750.3-6480.6$ & $>6480.6$ \\
\hline
\end{tabular}

The five rating groups are separated by the $10^{\text {th }}, 30^{\text {th }} 70^{\text {th }}$ and $90^{\text {th }}$ percentile. The scores ratings are presented in unscaled, ratio, scaled, and allometrically scaled values.

We compared also the ranking of 12 soccer players according to their Wingate power scores shown before (Test 1) and after participation in a specialized training program (Test 2). An example of the obtained results and the ranking in the average power achieved by each participant using unscaled and allometrically scaled data is presented in table 3 . In view of the relatively small sample of size new allometric exponents were retrieved: 0.995 for Test 1 and 1.094 for Test 2. Obviously, the ranking applied in the two methods differs significantly. 
Table 3. Participants ranking according to the Wingate Average Power (AP) during the preparatory and competition period of training, unscaled and allometrically scaled

\section{AP (W) during the preparatory period (Test 1)}

\begin{tabular}{cccccc}
\hline Ranking & Participant & $\begin{array}{c}\text { BM } \\
(\mathbf{k g})\end{array}$ & $\begin{array}{c}\text { Unscaled } \\
(\mathbf{W})\end{array}$ & Participant & $\begin{array}{c}\text { Allometrically scaled } \\
\mathbf{W . k g}^{-0,995}\end{array}$ \\
\hline 1 & A & 66,5 & 767,05 & A & 11,78 \\
\hline 2 & B & 60,0 & 611,6 & E & 11,30 \\
\hline 3 & C & 58,5 & 605,76 & D & 11,26 \\
\hline 4 & D & 57,5 & 585,31 & H & 11,24 \\
\hline 5 & E & 56,0 & 576,07 & B & 11,14 \\
\hline 6 & F & 53,0 & 568,19 & G & 11,01 \\
\hline 7 & G & 52,0 & 539,72 & L & 10,65 \\
\hline 8 & H & 50,0 & 501,85 & K & 10,31 \\
\hline 9 & N & 45,5 & 490,36 & C & 10,30 \\
\hline 10 & J & 44,0 & 439,61 & J & 10,18 \\
\hline 11 & K & 40,0 & 404,93 & F & 10,08 \\
\hline 12 & L & 38,0 & 397,51 & N & 8,56 \\
\hline
\end{tabular}

AP (W) during the competitive period (Test 2)

\begin{tabular}{cccccc}
\hline Ranking & Participant & $\begin{array}{c}\text { BM } \\
(\mathbf{k g})\end{array}$ & $\begin{array}{c}\text { Unscaled } \\
(\mathbf{W})\end{array}$ & Participant & $\begin{array}{c}\text { Allometrically scaled } \\
\mathbf{W} / \mathbf{k g}^{-1,094}\end{array}$ \\
\hline 1 & $\mathrm{~A}$ & 72,0 & 872,55 & $\mathrm{~A}$ & 8,11 \\
\hline 2 & $\mathrm{~F}$ & 65,5 & 704,5 & $\mathrm{G}$ & 7,98 \\
\hline 3 & $\mathrm{E}$ & 65,0 & 679,79 & $\mathrm{E}$ & 7,85 \\
\hline 4 & $\mathrm{C}$ & 62,0 & 677,42 & $\mathrm{H}$ & 7,81 \\
\hline 5 & $\mathrm{~B}$ & 59,0 & 657,37 & $\mathrm{~B}$ & 7,68 \\
\hline 6 & $\mathrm{G}$ & 58,5 & 646,31 & $\mathrm{~J}$ & 7,48 \\
\hline 7 & $\mathrm{~N}$ & 58,4 & 628,75 & $\mathrm{C}$ & 7,42 \\
\hline 8 & $\mathrm{D}$ & 55,5 & 582,07 & $\mathrm{~L}$ & 7,35 \\
\hline 9 & $\mathrm{H}$ & 49,0 & 551,34 & $\mathrm{~F}$ & 7,26 \\
\hline 10 & $\mathrm{~J}$ & 49,0 & 528,69 & $\mathrm{~K}$ & 7,24 \\
\hline 11 & $\mathrm{~L}$ & 44,0 & 461,31 & $\mathrm{D}$ & 6,79 \\
\hline 12 & $\mathrm{~K}$ & 44,0 & 454,57 & $\mathrm{~N}$ & 6,53 \\
\hline
\end{tabular}




\section{DISCUSSION}

The Wingate muscle power scores are considered as an important index of physical performance, particularly responsible for the success of rapid movements typical of soccer. They are applied to assess anaerobic capacity, to provide normative values for various kinds of sports, to evaluate the effect of training programs. The aim of this study was to derive allometric exponents for scaling WAnT power score that are effective in minimizing the body mass influence and to establish normative data for young soccer players.

The allometric exponents derived in this study $(0.72,0.78$ and 0.83 for PP, AP and W30 $\mathrm{s}$ respectively) using braking force $75 \mathrm{~g} .^{\mathrm{kg}-1}$ are markedly higher from the theoretical suggested of $b=0.67$ (Astrand and Rodahl, 1986). Many other allometric exponents for normalizing power data were proposed: Nedjelcovic et al (2009) determines allometric exponent 0.50 using braking force of $95 \mathrm{~g} .{ }^{\mathrm{kg}-1}$; Stickley et al (2013) proposed markedly higher allometric exponent for $\mathrm{PP}=0.89$ and for $\mathrm{AP}=0.86$ using braking force $100 \mathrm{~g}^{\mathrm{kg}-1}$. Despite the attempts to optimize the load when performing the Wingate test by increasing the resistance (Patton, 1985) considering the age of our contingent we stick to the classic $75 \mathrm{~g} \cdot{ }^{\mathrm{kg}-1}$. However, the differences in the applied experiments do not allow us to make a comparison with the data obtained in different studies.

The study shows the possibilities of applying allometric scaling to the coaches practice. There were twelve soccer players who accomplished a 5-month experimental training for improvement the speed/power and endurance. Additional intensive workloads were performed in the main part of some training activities. This approach was considered to be appropriate for developing speed endurance in groups of young athletes (Peev, 2017). Individual technique, tactics and physical resources are all important when evaluating performance differences in soccer players and it is difficult to discriminate between the relative importance of each of these elements when evaluating performance differences. The players improved significantly the power output in Test 2 compared with Test 1. The AP rose from $540.7 \pm 103.4$ Watt in Test 1 to $620,4 \pm 115,6 \mathrm{~W}$ in Test 2 (Chi Test $\alpha<0,001$ ). At the same time the boy's BM increased significantly: from mean $51.7 \pm 8.6 \mathrm{~kg}$ before Test 1 to $56.8 \pm 8.9 \mathrm{~kg}$ before Test 2, (Chi Test $\alpha<0,001)$. Obviously, this contributes to the improvement of the Wingate power scores. The players' ranking before (Test 1) and after the specialized training (Test 2) is different (Table 3). When absolute data for AP are used, heavier participants are overestimated. For example, during Test 2 player " $F$ " reaches $\mathrm{AP}=704.5 \mathrm{~W}$ with place in the rating $\# 2$. When the influence of BM is ignored by allometrically scaling, player " $F$ " is on position \#9. The reported allometric scores may be useful for coaches to more accurately assess the individual anaerobic power possibilities and to manage the training regimes.

\section{CONCLUSIONS}

The allometric exponents developed in the study have shown to be effective in minimizing the effect of BM on Wingate power scores. The use of these exponents in allometric scaling of young soccer players, WAnT power values provide coaches with valid means for comparing power production between individuals without the confounding influence of BM. 


\section{REFERENCE}

Astrand, P.O., Rodahl, K. (1986). Textbook of Work Physiology, New York, McGrav-Hill.

Bangsbo J., Norregaard L., Thorso F. (1991). Activity profile of competition soccer. Can J Sport Sci; 16 (2): 110-6.

Blair, T.C., Nicholas G., Robert P. Weatherby, T. (2009). A comparison of ratio and allometric scaling methods for normalizing power and strength in elite rugby union players. Journal of Sports Sciences Vol 27, 1575 1580.

Carling, C., Williams, A.M., Reilly, T. (2005). Handbook of soccer match analysis: a systematic approach to improving performance. London: Rout ledge.

Dooman, C.S, Vanderburgh, P.M. (2000). Allometric modeling of the bench press and squat: Who is the strongest regardless of body mass? J Strength CondRes 14: 32-36

Folland J.P, Mc Cauley, T.M, Williams, A.G.(2008). Allometric scaling of strength measurements to body size. Eur $J$ Appl Physiol. 102(6):739-45.

Hetzler, R.K, Stickley, C.D., Kimura, I.E.(2011). Allometric scaling of Wingate anaerobic power test scores in women. Res $Q$ Exerc Sport.Mar;82(1):70-8.

Inbar, O., Bar-Or,O, Scinner, J.S. (1996). The Wingate anaerobic test. Champaign: $\mathrm{Hu}-$ man kinetics Books.

Jaric, S. (2002). Muscle strength testing: use of normalisation for body size. Sports Med. 32(10):615-31.

Krustrup P., Mohr M., Ellingsgaard H., et al (2005). Physical demands during an elite female soccer game: importance of training status. Med Sci Sports Exerc, Jul; 37 (7): 1242-8.

Nedeljkovic, A., Mirkov, DM., Bozic, P., and Jaric, S. (2009). Tests of muscle power output: The role of body size. Int J SportsMed 30: 100-106.

Oba,Y., Hetzler, R.K., Stickley, C.D., Tamura, K., Kimura, I.F., Heffernan Jr, TP. (2014). Allometric scaling of strength scores in NCAA Division I-A football athletes. $J$ Strength Cond Res 28(12): 3330-3337.

Patton, J.F., Murphy, M.M., Frederick, F.A. (1985). Maximal power outputs during the Wingate anaerobic test. Int J Sports Med 6: 82-85.

Peev, P. (2017). Izsledvane na metodicheski podhodi za vuzdeistvie vurhu razvitieto na skorostnata isdrujlivost pri 13-14 godishni futbolisti. Dissertation PhD, NSA, Sofia.

Reilly T, Thomas V. (1976). A motion analysis of work-rate in different positional roles in professional football match-play. $J$ Hum Mov Stud; 2: 87-97.

Rienzi E., Drust B., Reilly T., et al. (2000). Investigation of anthropometric and work-rate profiles of elite South American international players. J Sports MedPhys Fitness; 40 (2):162-9.

Stickley, C.D, Hetzler, R.K, Wages, J.J, Freemyer, B.G, Kimura, I.F. (2013). Allometric scaling of Wingate anaerobic power test scores in men. J Strength Cond Res 27(9): 2603-2611.

Stefanova, D. (2002). Nyakoi promeni v homeostazata pri supramaksimalni natovarvania. Sportnofisiologichen analis. Avangard, Sofia.

Stefanova, D. (2002a). Alometrichnoto scalirane v sportnata fisiologia 1. Rabotosposobnost i telesna masa. Sport i nauka,1.

Stefranova, D. (2002b). Alometrichnoto scalirane v sportnata fisiologia 2. EPOC kato funkcia ot dve velichini. Sport i nauka, 2.

Stølen T., Chamari K., Castagna C., Wisløff U. (2005). Physiology of soccer: anup- 
date. Sports Med.;35(6):501-36.

Vanderburgh, P.M., Mahar, M.T., Chou, C.H. (1995). Allometric scaling of grip strength by body mass in college-age men and women. Res $Q$ Exerc Sport 66: 80-84.
Vanderford M.L., Meyers W.A., Skelly C.C., Steward, Hamilton K.L. (2004). Physiological and sport-specific skill responses of Olympic youth soccer athletes. J.Strength Cond. Res. 18(2):334-342.

\section{Corresponding author:}

Borislava Petrova

Center for Research and Applied Activity in Sport

National Sports Academy "Vassil Levski" Studentski grad, 21, Acad. Stefan Mladenov str.

Sofia 1700, Bulgaria

E-mail: bubetokp79@gmail.com 